\title{
Catecholamines in Experimental Spinal Cord Lesion Associated with Spinal Arachnoiditis ${ }^{\star}$
}

Hirofumi Ishioka, M.D., Takaaki Ikata, M.D. and Hideta Hasegawa, M.D. Department of Orthopaedic Surgery, School of Medicine, Tokushima University

\begin{abstract}
Catecholamines in the spinal cord and cerebro-spinal fluid were measured by a radio-enzymatic assay technique after cisternal kaolin injection in 30 dogs. Noradrenaline in the grey matter of the cervical cord and the cerebrospinal fluid showed the highest level (an average of $127.8 \mathrm{ng} / \mathrm{g}$ and $856.0 \mathrm{ng} / \mathrm{ml}$ ) in the first week, while that of the thoracic and thoracolumbar cord showed a gradual rise to an average 175.0 and $210.0 \mathrm{ng} / \mathrm{g}$ in the twelfth week. No significant changes were found in dopamine and adrenaline in both the grey and white matter. The noradrenaline increment in the grey matter was more related with degenerative cord lesions in all segments, while most of segments with cavitation showed the low level of noradrenaline.
\end{abstract}

